\title{
Numerical Analysis of Needle Valve for Cryogenics Application
}

\author{
Aniket Balande ${ }^{+*}$, D. S. Watvisave ${ }^{\dagger}$ and Tansen Chaudhari ${ }^{\#}$ \\ †Department of Mechanical Engineering, Sinhgad College of Engineering, Pune-41, India \\ \#Fluid Controls Pvt. Ltd. Bhosari, Pune-41, India \\ Accepted 15 June 2016, Available online 20 June 2016, Special Issue-5 (June 2016)
}

\begin{abstract}
Valves are grouped into critical components of the system. It is necessary to analyze the performance of valve before it actually being used in system. Parts of valve operating at higher temperature expands which improves sealing and leakage rate is reduced, but in case of valves operating at cryogenic temperature valve parts are subjected to nonuniform contraction which leads to disturbed geometry and causes more leakage. In this paper analysis of 3/4" needle valve at cryogenic temperature is performed to understand the different parameters. Flow analysis of needle valve using CFD code is performed at cryogenic temperature to identify the parameters like pressure, velocity. Thermo mechanical analysis is done to analyze the effect of cryogenic temperature on the valve structure.
\end{abstract}

Keywords: Needle Valve, Cryogenics, Computational Fluid Dynamics (CFD), Analysis

\section{Introduction}

Cryogenics is study of production and behavior of materials at very low temperature. The temperature at which cryogenic start is not exact value but it is assumed that it starts below $-150^{\circ} \mathrm{C}\left(123 \mathrm{~K} ;-238^{\circ} \mathrm{F}\right)$. In cryogenic applications two areas are considered one is properties of cryogen, and another one is related to changes in the behavior of material of the system component, which are subjected to very low temperature and high pressure. Cryogenics has got different application in space, in mechanical engineering, in medicine, in super conductivity etc. In many applications cryogenic valves are used to control the flow of cryogenic fluid, for example Cryogenic ball valve is used to control the liquefied natural gas which temperature is at temperature $-196{ }^{\circ} \mathrm{C}$ and also valves are used in liquid hydrogen supply lines of space shuttle. In particular system valves are grouped into most critical components of the system. Therefore selecting valve, material of valve, design of valve for particular cryogenic application is very important so that valve will operate accurately as system required. Many time valve required to function at most extreme condition. Due to pressure difference at inside and outside of valve and contraction of valve at cryogenic temperature leakage is caused from the fittings of valve.

Design of valve for cryogenic applications required special considerations as compared to valve used at normal temperature. For example, the valve design must take into consideration thermal contraction and should still provide tight seal so that leakage will not

*Corresponding author: Aniket Balande occur in the seat. 'Liquid lock' is another undesirable process which occurs in valves operating at cryogenic temperature in which, some liquid gets trapped in a cavity within the valve body at the time of closing or opening the valve. This is dangerous because liquefied refrigerated gases, which are trapped in cavity, may exert sufficient pressure on expansion to cause plastic deformation of components, or ultimately failure of valve.

In this study analysis on $3 / 4$ " needle vale is performed, flow analysis is performed to find out the pressure drop from inlet to outlet. Leakage rate is function of pressure difference which is calculated above. Thermal and mechanical coupling analysis is done to calculate the effect of the cryogenic temperature on the structure of valve.

Performance of valve at cryogenic temperature is tested using cryogenic leakage testing. Helium or nitrogen is used as test gas in cryogenic testing facility for the measurement of performance of cryogenic valves. Liquid nitrogen is very economical way than the other gases to lower its temperature from room temperature to cryogenic temperature. Liquid helium is also commonly used as it allows to attain the lowest temperature. The cryogenic leak test requires cryogenic instrumentation for example Dewar flask is used to store the cryogenic fluid, the supply lines are designed considering cryogenic temperature. In order to maintain tested fitting at cryogenic temperature, it is necessary to supply refrigeration continuously to remove the heat transferred by radiation, convection and conduction from the surrounding. 


\section{Literature Survey}

Performance testing and leak testing of cryogenic valve must be carried out before it is being used in the cryogenic liquid handling system as it is more critical application than normal temperature flow control application. Dong-Soo KIM and Myoung-Sub KIM examined the performance characteristics of the parts of high pressure, cryogenic ball valves. In this paper Numerical analyses of the strength and thermal shock was conducted, also seat structure was investigated and tested. For strength test seismic analysis is done for maximum acceleration of $2 \mathrm{~g} \mathrm{~m} / \mathrm{s}^{2}$. By conducting the thermal stress analysis at high pressure and very low temperature, a maximum stress of $23.9 \mathrm{kgf} / \mathrm{mm}^{2}$ occurred at the center of the ball. The flow characteristics of the ball valve were analyzed with inlet and outlet pressures of $168 \mathrm{~kg} / \mathrm{cm}^{2}$ and 80 $\mathrm{kg} / \mathrm{cm}^{2}$ respectively, to obtain the velocity distribution and eddy flow of LNG according to the valve position.

Moore, et al. [2] carried cryocooler test for development and testing of passive check valve, the valve was assembled and installed conventionally, one additional step was conducted in this experiment to improve the sealing. The sealing material used is PTFE which goes under phase transition at about $170 \mathrm{~K}$, but it gets soften if temperature goes above $-295 \mathrm{~K}$. To improve sealing, the valve is immersed in a bath of 50 ${ }^{\circ} \mathrm{C}$ water and the valve is sealed with a preload pressure difference of $10 \mathrm{psi}$. The results of tests on a pulse tube cryocooler setup prove a scaling argument which can be used to predict the sealing flow rate of a valve using results from tests at liquid nitrogen temperatures. A more effective method for preforming the reed valve is also discussed, resulting in orders of magnitude improvement over other methods. This improved iteration can be scaled to different temperatures, providing a versatile passive check valve for various cryogenic applications.

Work done by Nellis and Maddocks provided the basis for the design of the check valve for a hybrid Pulse Tube/Reverse Brayton (PT/RB) cryocooler. It is found that the PT/RB had both higher pressures and lower flow rates than the CCDR.

The leakage is small unwanted liquid or gas flow out of the valves (or fitting) through slight gap between joint sealing surfaces, caused by cooling contraction of mating parts. Leakage depends on five factors i.e. differential pressure, fluid viscosity, diameter of seal, length of seal and cube function of sealing gap between two sealing surfaces. Veenstra, et al. designed, manufactured and tested a very low leakage stainless steel seated, gold coated, reed type valve for application in a sorption compressor. The sealing rate was found to be as low as $6 \mu \mathrm{g} / \mathrm{s}$ with a sealing pressure of 10 bar.

Scarborough presented in his paper that the ice bridge which can be formed is such as to require a negligible shearing force and the stem can be sealed against leakage at very low temperatures. Therefore, no stem extension is required. The valve is also sealed so that the entrance of moisture from the outside air which otherwise might form an ice bridge at the main stem seal is prevented.

Oza et al, carried out the CFD simulation to understand the performance of globe valve for oxygen flowing at high pressure through it. In this paper axisymmetric numerical model is used for the prediction of flow characteristics for globe style flow control valve. The turbulent kinetic energy increases as the plug retracted beyond the plane of seat. The k-w model gave higher values of velocity and turbulent kinetic energy than the k-e model since the latter captures lesser recirculation and is more suitable for boundary level flow.

\section{Needle Valve}

Needle valves are used in variety of industries to regulate the flow of fluid very precisely. Generally it is used to control the flow passing through gauges to avoid damage due to high pressure fluid flow. Needle valves are used in application where flow of fluid must gradually decrease or the application where very less flow rate is required, also it is useful in throttling application. Needle valves have a slender, tapered point at the end of the valve stem that is lowered through the seat to restrict or block flow. Fluid flowing through the valve turns 90 degrees and passes through an orifice that is the seat for a rod with a cone shaped tip. Different parts of needle valve are body, bonnet, bonnet nut, stem, packing, handle. Stainless Steel or Cast Iron is generally used for design of body, bonnet, handle and other parts of valve. PTFE or Grafoil is used for the packing. Figure 1 shows the needle valve.

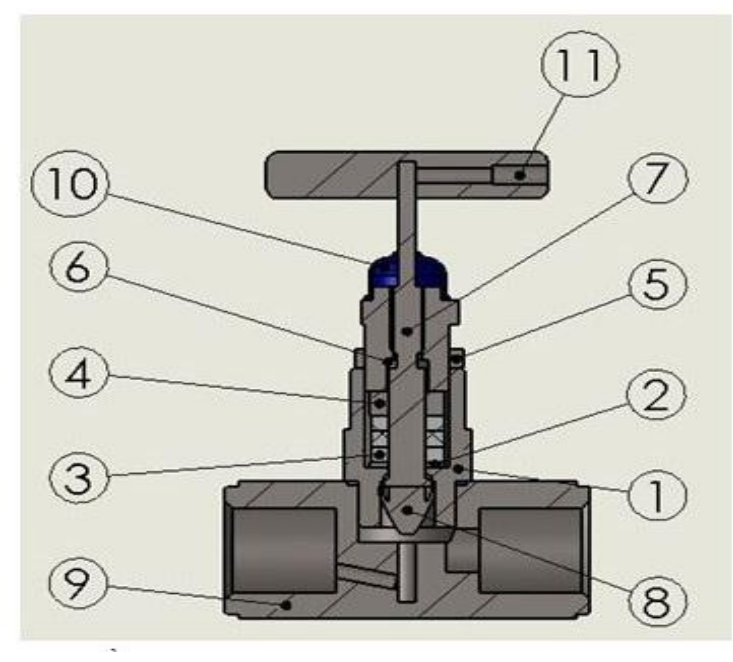

Fig. 1 Section view of needle valve

Following table represents the different parts and material used for manufacturing of needle valve which is used in analysis. 
Table No. 1 Description of needle valve parts and material used

\begin{tabular}{|c|c|c|}
\hline No. & Description & Material \\
\hline 1 & Bonnet & A 479 SS 316 \\
\hline 2 & Gland seat washer & A 479 SS 316 \\
\hline 3 & Gland seal & PTFE \\
\hline 4 & Gland retainer & A 479 SS 316 \\
\hline 5 & Check nut & A 276 SS 304 \\
\hline 6 & Gland & A 276 SS 304 \\
\hline 7 & Spindle & A 276 SS 304 \\
\hline 8 & Spindle plug & A 276 SS 304 \\
\hline 9 & Body & A 479 SS 316 \\
\hline 10 & Dust cap & POLYPROPYLENE \\
\hline 11 & Handle & A 479 SS 316 \\
\hline
\end{tabular}

\section{CFD Analysis of Needle Valve}

Fluid flow analysis is performed using CFD code ANSYS FLUENT V15. Figure 2 (a) and (b) show the model and meshed fluid domain respectively. Modeling of valve is done using CAD software SOLIDWORKS. Model of needle valve is imported in ANSYS ICEM meshing software to extract the flow domain and perform volume meshing on that. Meshing at the boundary at which fluid and valve is in contact, is made fine compared to inside volume to capture the boundary effect. Tetrahedral type of meshing is used in which number of elements are 484296 and nodes are 84702 . Boundary condition at inlet is pressure inlet and it is equal to $264 \mathrm{~kg} / \mathrm{cm}^{2}$ and temperature at which liquid nitrogen is flowing is equal to $-150{ }^{\circ} \mathrm{C}$. Boundary condition at outlet is pressure outlet which is atmospheric pressure. Viscous-laminar model is used for the solution. SEMPLE method is applied for the discretization of fluid domain which is responsible for convergence of solution.

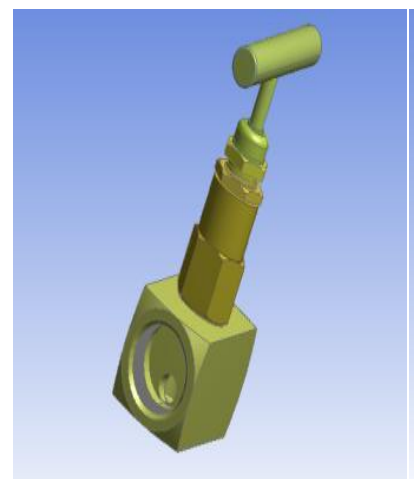

(a)

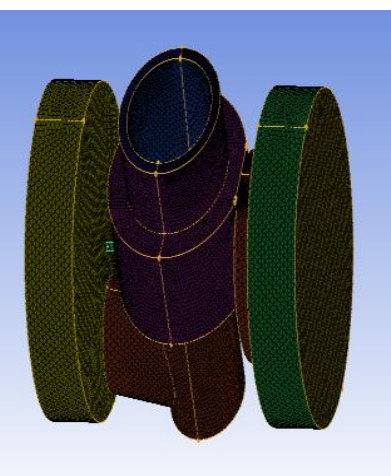

(b)
Fig. 2 (a) Model of Needle Valve, (b) Meshed Fluid Domain

Flow analysis is performed to obtain the velocity and pressure distribution along the valve. Figure 3 shows velocity distribution along the valve at open condition. At different position planes are created to represent the velocity profile in the valve. It can be seen that velocity at the center of each flow domain is higher compared to velocity of flow near the wall, representing boundary layer formation due to no sleep condition.

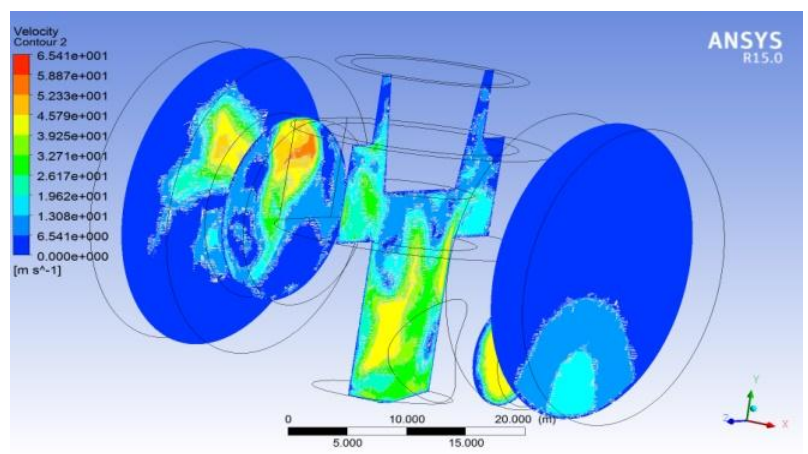

Fig. 3 Velocity distribution along the valve

Figure 4 shows the pressure distribution inside flow domain of Needle Valve, maximum pressure is at inlet with decreasing pressure towards outlet representing pressure drop in the valve. It is seen that there is large pressure drop from inlet to outlet, as required in needle valve. Inlet pressure is $264 \mathrm{Kg} / \mathrm{cm}^{2}$ and outlet pressure is $65 \mathrm{~kg} / \mathrm{cm}^{2}$. In throttling process large pressure drop is required to obtain constant enthalpy, therefore this needle valve is suitable for this throttling application. This pressure profile represent the variable distributed load in the valve which is used to calculate leakage through valve.

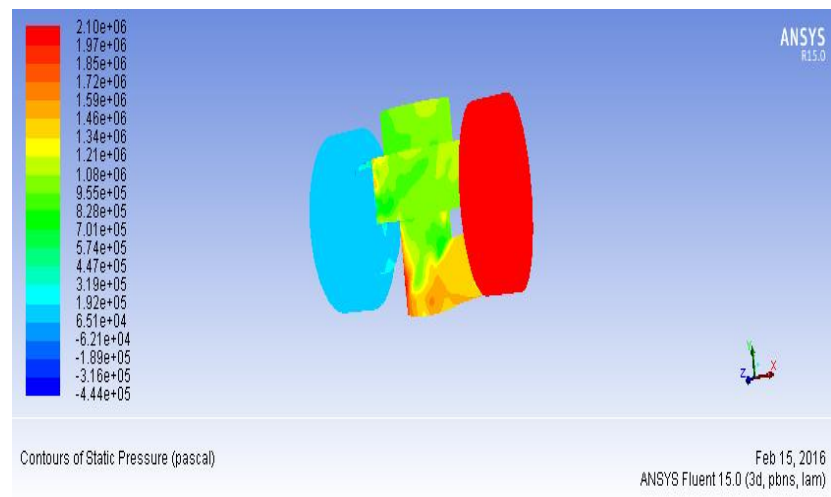

Fig. 4 Pressure distribution along the valve

\section{Thermal Analysis of Needle Valve}

Coupling of mechanical and thermal analysis is done to understand the effect of cryogenic temperature and internal pressure on the valve at the same time. In this analysis first steady state thermal analysis is performed with boundary condition of inside temperature of valve $-150{ }^{\circ} \mathrm{C}$. Model of valve was imported in the ANSYS workbench, different parts where assigned with there respective material. Meshing of valve is done with maximum element size of $1 \mathrm{~mm}$ to obtain the fine meshing and capture each geometry. Total number of elements are 353978. Boundary condition that is temperature $-150{ }^{\circ} \mathrm{C}$ is 
applied on the internal faces of valve where fluid will be in contact with it. Steady state thermal profile is obtained at the end of this analysis. This thermal profile is taken as input to the static structural analysis, also boundary condition of internal pressure of 400 $\mathrm{kg} / \mathrm{cm}^{2}$ is applied which is maximum working pressure and valve is fixed at the ends. At the end of this analysis thermal stress, deformation and stain is calculated. Figure 5 represents the stress induced in valve which is equal to $67.439 \mathrm{MPa}$. Maximum stress obtained is large therefore it is required to consider in design of valve. Maximum deformation obtained is $0.2734 \mathrm{~mm}$.

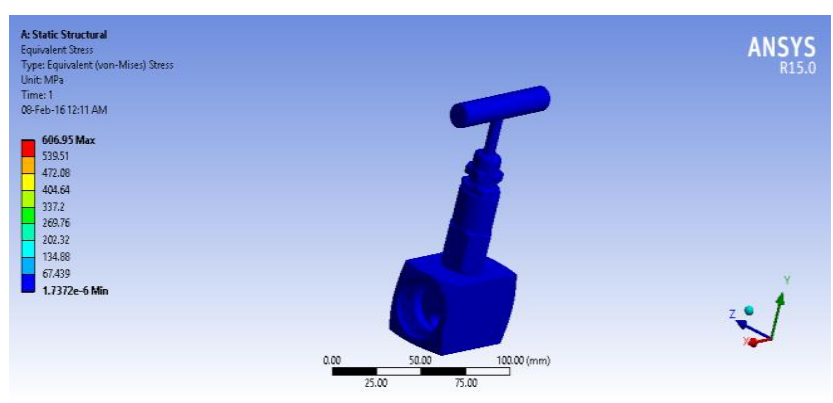

Fig. 5 Stress induced in the valve

\section{Experimental Analysis of Needle Valve}

Cryogenic leak testing is performed to find out the leakage at very high pressure and at very low temperature. In test setup lowest temperature that can be reached is $-196{ }^{\circ} \mathrm{C}$ and maximum pressure at which valve can be tested is 60 bar. Following are the detailed description of experiment.

\subsection{Test medium}

The high pressure helium gas is used as cryogenic search gas instead of liquid cryogen because of its advantages such as safety of operation, simplicity of instrumentation, ease of detectability, as well as inertness, high permeation rate, high thermal conductivity, low boiling point, and low cost, which make it the ideal medium for cryogenic leak detection.

\subsection{Test method}

Leak test is primarily for determining whether the leak is greater than the tolerable amount. Over pressure sample vacuum chamber test is applied. The search gas escaping through the gaps of the tested fitting into an evacuated chamber is indicated by vacuum gauges and either helium mass spectrometer, or helium gas flow meter, which can be connected to sample chamber. If the helium mass spectrometer is used, the method allows the measurement of large leaks.

\subsection{Test condition}

The operating temperature of tested fittings could be varied over the range from liquid helium temperature to room temperature and held fixed at any intermediate points within this range. The operating pressure of search gas within the tested fittings could be varied over the range from $1 \mathrm{~atm}$ to $65 \mathrm{~atm}$ and could be maintained constant at any intermediate point within this range even when the pressure drop during the cooling period. The cryogenic leak detection process at the above temperature and pressure conditions will not impose any limitation on operating time of the test. Fig 6 represents the

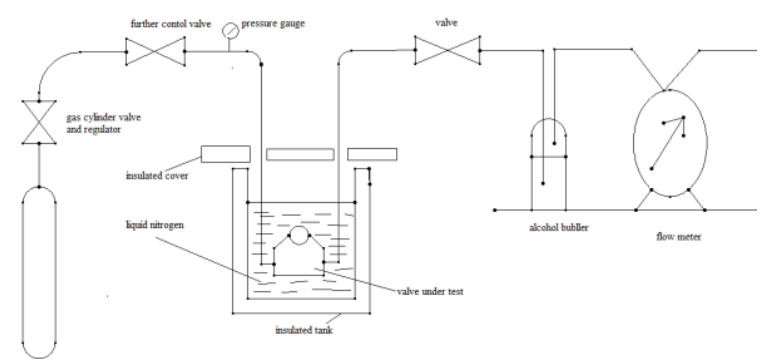

Fig. 6 Cryogenic Valve test system

\subsection{Procedure to carry out cryogenic test}

The valve to be tested is submerged in liquid $\mathrm{N}_{2}$ and allowed to cool down. When equilibrium has been reached the liquid $\mathrm{N}_{2}$ will stop boiling. The valve should then be closed and helium introduced as shown in diagram 1. It is normal for small bubbles to rise from all over the valve due to very small quantities of heat passing from the valve to the liquid and these need not cause concern. Bubbles from the joints, stem packing or outlet are signs of leakage. These tests are very stringent because, in accordance with Graham's Law of Diffusion, Helium can show up leakages that will not happen with fluids with higher molecular weights. The use of liquid $\mathrm{N}_{2}$ at $-196^{\circ} \mathrm{C}$ for testing also gives an extra margin compared with testing on the actual cargo liquid. The use of liquid $\mathrm{N}_{2}$ instead of LNG also avoids flammability hazards on the test rig. Fig 7 shows the Cryogenic leak test rig.

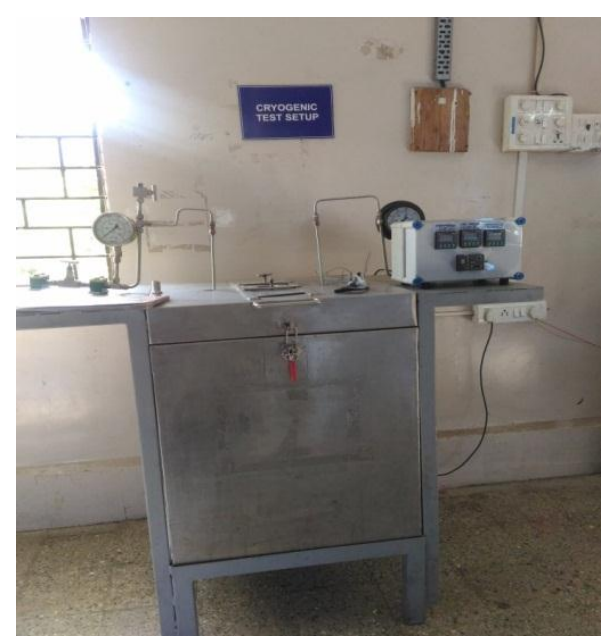

Fig. 7 Cryogenic Test Setup 


\subsection{Leak rate calculations}

The expression for leak rate given by engineering standards committee on control valves of fluid control institute. Leak flow is assumed as laminar flow, with the exception of entrance and exit losses. As a Poiseuille type flow, the volumetric leak flow rate is expressed as:

$Q=\frac{1}{12} \frac{\Delta P \Pi D}{\mu \mathrm{L}} H^{3}\left(\mathrm{~m}^{3} \mathrm{~s}^{-1}\right)$

This equation reviles that the amount of leakage depends on following five factors:

Differential pressure $(\Delta P)$

Fluid viscosity $(\mu)$

Diameter of seal (D)

Length of seal (L)

Cube function of sealing gap $(\mathrm{H})$

Since one can not generally control the operating pressure, fluid viscosity, sealing diameter and more or less sealing sealing length, one must work with sealing gap to achieve reliable and repeatable seal.

\section{Conclusions}

Analysis on Needle valve for cryogenic application is performed to understand the different parameters that are required for the design of valve. Needle valve is used for throttling purpose in which pressure drop required is very high and this valve is satisfying the purpose as there is large pressure drop from inlet to outlet and also velocity at inlet is less than velocity at outlet.
At cryogenic temperature with internal pressure applied valve is subjected thermal deformation of $0.2734 \mathrm{~mm}$ which is to be considered while design of valve. Thermal deformation calculated is used to calculate leakage rate. Above analysis is required to be validated with the experimental analysis of valve for that purpose cryogenic leak testing is to be performed.

\section{References}

DongSoo KIM, MyoungSub KIM(2008), Analysis and design of Cryogenic Ball Valve by, Proceedings of the 7th JFPS International Symposium on Fluid Power, TOYAMA. pp. 1518.

B.D. Moore, J.R. Maddocks, F.K. Miller(2013), Development and Testing of a Passive Check Valve for Cryogenic Applications, Elsivier publications. pp. 169-172

Jin-yuan Qian et al (2014), CFD analysis on the dynamic flow characteristics of the pilot-control globe valve, Energy Conversion and Management, Elsivier publications , 87, pp. 220-226.

Veenstra T. T. et al (2007), Development of a Stainless Steel Check Valve for Cryogenic Applications. Cryogenics(47), 121-126.

W. Scarborough (1960), Cryogenic valve, Collin, Egypt, United States Patent Office, pp. 251-214.

Aditi oza et al (2007), CFD modeling of Globe valve for Oxygen Application,. published at $16^{\text {th }}$ Australasian fluid mechanics conference, crown plaza, gold coast, Australia, pp. 1356-1362.

L.X. Jia, et al, Cryogenic leak testing of tube fitting/valves, department of mechanical engineering, florida Atlantica University, Boca Raton, FL33431, USA. 